\title{
The clinical importance of overweight or obesity on tumor recurrence in papillary thyroid carcinoma
}

\author{
Jung Min Kim^ \\ Department of Internal Medicine, Sanggye Paik Hospital, Inje University College of Medicine, Seoul, Korea \\ Correspondence to: Jung Min Kim, MD, PhD. Department of Internal Medicine, Sanggye Paik Hospital, Inje University College of Medicine, 761-1, \\ Sanggye-7dong, Nowon-gu, Seoul 139-707, Korea. Email: jmkim.benaiah@paik.ac.kr.
}

Backgrounda Obesity is known to common, preventable, and modifiable cause of carcinogenesis. Obesity
may be associated with the risk and prognosis of papillary thyroid carcinoma (PTC), but the results of studies
are controversial. We studied whether overweight or obesity would be associated with poor prognoses, such
as tumor recurrence in PTC patients.

Methods: PTC patients at a single institution were retrospectively reviewed.

Results: A total of 403 PTC patients (352 women and 51 men; mean age, 48 years) were enrolled. They underwent total thyroidectomy or lobectomy from January 2000 through December 2010. One-hundred forty-eight cases (37\%) were categorized as overweight or obese [body mass index (BMI) $\geq 25 \mathrm{~kg} / \mathrm{m}^{2}$ ]. I found a significant association between overweight or obesity and multifocality $(\mathrm{P}=0.006)$. In multivariate analyses adjusting for poor prognosis factors, such as age, gender, tumor size, and extrathyroid extension (ETE), this association disappeared. There was a significant association between overweight or obesity and tumor recurrence; $13 \%$ vs. $5 \%$ with and without overweight or obesity, respectively $(\mathrm{P}=0.008$ by log-rank test, median follow-up period: 10.5 years). However, this association was also lost on multivariate analysis adjusting for poor prognosis predictors of recurrence.

Conclusions: Overweight or obesity might be associated with poor prognosis factors. However, they might not be associated with tumor recurrences of PTC.

Keywords: Obesity; papillary thyroid carcinoma (PTC); tumor recurrence

Submitted Oct 12, 2021. Accepted for publication Dec 22, 2021.

doi: $10.21037 /$ gs-21-695

View this article at: https://dx.doi.org/10.21037/gs-21-695

\section{Introduction}

Obesity is known to increase the risk of cancer (1), as well as type 2 diabetes and cardiovascular disease. Excessive weight has been linked to an increased risk of several cancer types. It is estimated that $40 \%$ of all cancers in the United States are due to overweight and obesity (2). The strength of the association and types of cancer varies between studies, but several meta-analyses have found strong evidence supporting an association between obesity and several cancers $(3,4)$.

Several meta-analyses have reported that obesity is a risk factor for thyroid cancer (5-7). Potential mechanisms in the possible association between obesity and cancers have included insulin, cytokine, adipokines, estrogen, or thyroidstimulating hormone (TSH) (8). Recent studies reported obesity was associated with poor prognostic factors such as tumor size $(9,10)$, multifocality $(9-12)$, extrathyroid

\footnotetext{
^ ORCID: 0000-0002-1848-3747.
} 
extension (ETE) (9-13), or advanced tumor-node-metastasis (TNM) staging $(9,10,13)$.

Obesity has been assessed in clinical practice as body mass index (BMI). BMI is expressed as the ratio of body weight $(\mathrm{kg})$ divided by height in squaremeter $\left(\mathrm{kg} / \mathrm{m}^{2}\right)$. A J-shaped relationship between BMI and mortality/morbidity has been reported in many extensive population studies $(14,15)$. A BMI $\geq 30 \mathrm{~kg} / \mathrm{m}^{2}$ (which defines obesity in many guidelines) is associated with increased morbidity/mortality. However, the World Health Organization Asia-Pacific region and the Korean Society of Obesity defined obesity as a $\mathrm{BMI} \geq 25 \mathrm{~kg} / \mathrm{m}^{2}$, based on evidence for a significant increase in obesity-related diseases $(16,17)$. I will use the BMI $\geq 25 \mathrm{~kg} / \mathrm{m}^{2}$ and mark it as overweight or obese to avoid confusion.

I evaluated whether overweight or obesity is associated with poor prognoses, such as multifocality, ETE, cervical lymph node (CLN) metastasis, and tumor recurrence in patients with PTC using BMI.

I present the following article in accordance with the STROBE reporting checklist (available at https:// gs.amegroups.com/article/view/10.21037/gs-21-695/rc).

\section{Methods}

\section{Subjects}

I enrolled patients undergoing for with PTC in chronological order from January 2000 through December 2010. They underwent total thyroidectomy or lobectomy with or without lymph node dissection and/or subsequent ${ }^{131}$ I remnant ablation treatment at Sanggye Paik Hospital, Seoul, Korea. Medical records of the subjects were retrospectively reviewed including pre-operative body weights, heights, BMI and laboratory tests such as serum fasting glucose level, total cholesterol level, and TSH level. A detailed histopathologic report included information about the tumor diameter, mulfocality, ETE, and CLN metastasis. I excluded patients without body weights, heights, or laboratory tests.

\section{Follow-up protocol \& definition of recurrence}

I regularly performed physical examination and chest radiography in all PTC patients. I measured serum thyroglobulin, anti-thyroglobulin antibody, and TSH yearly. All patients underwent neck ultrasonography yearly. I performed radiologic studies, including neck ultrasonography, ${ }^{18} \mathrm{~F}$-deoxyglucose positron emission tomography, or chest computerized tomography if clinical or biochemical data suggested tumor recurrence. I localized the normal or malignant thyroid tissue.

I defined recurrence as the re-appearance of PTC after complete ablation of postsurgical thyroid remnants, and I confirmed recurrence by cytological and/or histopathological examination. I excluded patients with distant metastasis at the time of initial diagnosis from the analysis of recurrence.

\section{Variables}

I included patients' characteristic data, such as age and sex, and the tumor findings: tumor size, ETE (no/microscopic/ macroscopic), multifocality (no/yes), CLN metastasis and $\mathrm{N}$ categories $(\mathrm{N} 0 / \mathrm{N} 1 \mathrm{a} / \mathrm{N} 1 \mathrm{~b} / \mathrm{Nx})$ using TNM staging system proposed by the American Joint Committee on Cancer $\left(7^{\text {th }}\right.$ ed.). The following laboratory findings were included such as serum fasting glucose $(\mathrm{mg} / \mathrm{dL})$, total cholesterol $(\mathrm{mg} / \mathrm{dL})$, and TSH $(\mu \mathrm{IU} / \mathrm{mL})$.

The study was conducted in accordance with the Declaration of Helsinki (as revised in 2013). The study was approved by Institutional Review Board of Inje University Sanggye Paik Hospital (No. SGPAIK 2021-11027) and individual consent for this retrospective analysis was waived.

\section{Statistical analysis}

I presented categorical variables as numbers and percentages, and I compared using chi-square or Fisher's exact test. I presented continuous variables as mean \pm SD and range. I performed binary logistic regression analysis to assess the relationship between BMI and other possible prognostic factors. I used the Kaplan-Meier method, including the log-rank test, to compare tumor recurrence. The endpoint for the analysis of disease-free survival was any relapse of PTC. I used Cox's proportional hazard model and the stepwise forward method to analyze the relative importance of various prognostic factors for postoperative survival and tumor recurrence. The possible prognostic factors analyzed included age, gender, and the absence or presence of CLN metastasis. A P value of $<0.05$ was considered significant. I performed all statistical analyses using SPSS (version 25.0; IBM Corp., Armonk, NY, USA). 
Table 1 The clinicopathological characteristics according to BMI

\begin{tabular}{|c|c|c|c|}
\hline Variable & $\mathrm{BMI}<25 \mathrm{~kg} / \mathrm{m}^{2}(\mathrm{~N}=255)$ & $\mathrm{BMI} \geq 25 \mathrm{~kg} / \mathrm{m}^{2}(\mathrm{~N}=148)$ & $P$ value \\
\hline Gender (M:F) & $21: 234$ & $30: 118$ & $<0.001^{\mathrm{b}}$ \\
\hline The number of near total or total thyroidectomy, $\mathrm{n}$ [\%] & 224 [88] & 136 [92] & $0.20^{b}$ \\
\hline Size $(\mathrm{cm})$ & $1.4 \pm 1.0$ & $1.3 \pm 0.9$ & $0.59^{\mathrm{a}}$ \\
\hline Extrathyroid extension, $\mathrm{n}$ [\%] & & & $0.30^{b}$ \\
\hline No extension & $120[47]$ & $61[41]$ & \\
\hline Minimal extension & $128[50]$ & $83[56]$ & \\
\hline Gross extension & 7 [3] & $4[3]$ & \\
\hline $\mathrm{N} 1 \mathrm{a}$ & 66 [26] & $45[30]$ & \\
\hline $\mathrm{N} 1 \mathrm{~b}$ & $13[5]$ & $7[5]$ & \\
\hline $\mathrm{Nx}$ & $62[24]$ & 32 [22] & \\
\hline TSH $(\mu \mathrm{IU} / \mathrm{mL})$ & $2.13 \pm 1.85$ & $2.24 \pm 1.97$ & $0.59^{a}$ \\
\hline Fasting glucose (mg/dL) & $104 \pm 26$ & $110 \pm 24$ & $0.03^{a}$ \\
\hline Total cholesterol (mg/dL) & $188 \pm 37$ & $200 \pm 39$ & $0.003^{a}$ \\
\hline
\end{tabular}

Percentages are given in parentheses. ${ }^{a}$, by Student's $t$-test; ${ }^{b}$, by Fisher's exact test. BMI, body mass index; TSH, thyroid stimulating hormone.

\section{Results}

\section{Clinicopathological characteristics (Table 1)}

I enrolled 403 patients with PTC, who underwent total thyroidectomy or lobectomy with or without CLN dissection. One hundred forty-eight patients (37\%) had overweight or obesity defined as $\mathrm{BMI} \geq 25 \mathrm{~kg} / \mathrm{m}^{2}$. Nineteen patients (5\%) had a BMI $\geq 30 \mathrm{~kg} / \mathrm{m}^{2}$.

Mean age, ratio of near total or total thyroidectomy, tumor size, extrathyroid extension, and CLN metastasis were not significantly different between BMI $<25 \mathrm{~kg} / \mathrm{m}^{2}$ (non-obese) and $\mathrm{BMI} \geq 25 \mathrm{~kg} / \mathrm{m}^{2}$ (overweight or obese) groups. Compared with patients with non-obese group, overweight or obese group demonstrated higher ratio of male $(\mathrm{P}<0.001)$ and higher multiple PTC $(\mathrm{P}=0.006)$.

There was no significant difference in serum TSH level between non-obese and overweight or obese groups. Compared with patients with non-obese group, overweight or obese group had higher fasting glucose level $(\mathrm{P}=0.03)$ and higher fasting total cholesterol level $(\mathrm{P}=0.003)$.

\section{Recurrence, disease-free survival (Figure 1)}

Thirty-three patients $(8 \%)$ had tumor recurrence. overweight or obesity was significantly associated with tumor recurrence during the follow-up period (median 125 months): $5 \%$ (14 patients) of non-obese group compared with $13 \%$ (19 patients) of overweight or obese group ( $\mathrm{P}=0.008$ by log-rank test; Figure 1). Multivariate analysis adjusting for conventional clinicopathological predictors of recurrence lost this significant association (Table 2).

\section{Multivariate analysis of the association of obesity with various clinicopathological parameters (Table 3)}

Multivariate analysis was used to analyze associations between overweight or obesity and various clinicopathological prognosis factors used for predicting recurrence, such as age, gender, tumor size, multifocality, ETE, CLN metastasis, serum TSH, fasting glucose, and fasting total cholesterol level. After multivariate analysis adjusting 


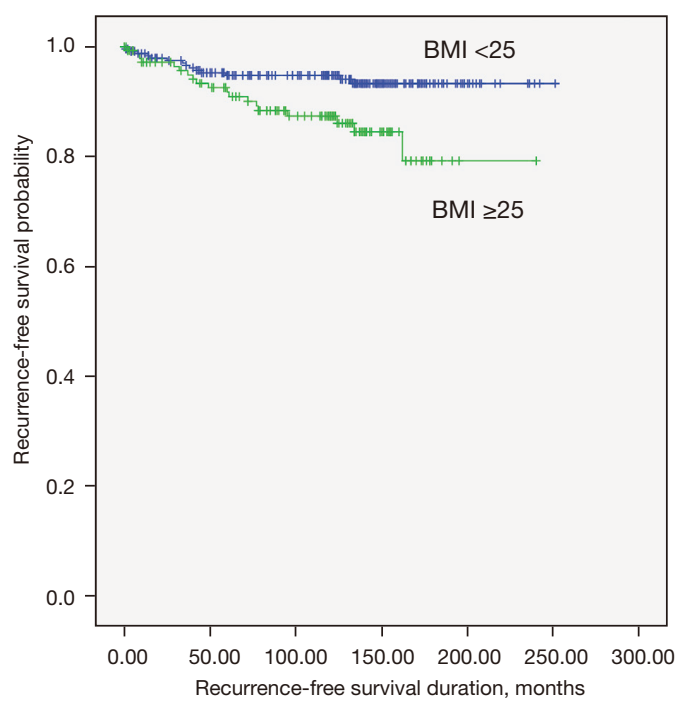

Figure 1 Disease-free survival according to body mass index (BMI, $\mathrm{kg} / \mathrm{m}^{2}$ ) in 403 patients without distant metastasis at the time of initial diagnosis. The Kaplan-Meier method for recurrence with the log rank test was used for statistical comparisons.

for clinicopathological prognosis factors, the association between overweight or obesity and gender $(\mathrm{P}=0.002)$ and serum fasting glucose level remained significant $(\mathrm{P}=0.003)$.

\section{Discussion}

In this study, I evaluated whether overweight or obesity would be associated with poor prognoses, such as tumor recurrence in PTC patients. I found that overweight or obesity associated with multifocality and tumor recurrence in patients with PTC. Multivariate analysis adjusting for conventional clinicopathological predictors of tumor recurrence lost these associations with overweight or obesity and multifocality, tumor recurrence.

Although not looked at in our study, is obesity a risk factor for thyroid cancer? The strength of the association between obesity and types of cancer varies among studies. Still, several meta-analyses have found strong evidence supporting an association between obesity and several cancers, but not thyroid cancer $(3,4)$. In a study of more than 170,000 Korean postmenopausal women, there was no association between obesity and thyroid cancer (18).

On the contrary, a large meta-analysis showed there was a strong association between a $5 \mathrm{~kg} / \mathrm{m}^{2}$ increase in BMI and thyroid cancer in men [relative risk (RR) $1.33, \mathrm{P}=0.02$ ] and there was a weaker positive association in women (RR
$<1.20$ ) (1). A cohort study based on BMI $30 \mathrm{~kg} / \mathrm{m}^{2}$ reported RR for thyroid cancer was 1.89 (95\% CI: 1.21-2.96) in men, while RR was 1.10 (95\% CI: 0.75-1.61) in women(19). A cohort study of radiologic technologists' risk of thyroid cancer based on BMI $\geq 35 \mathrm{~kg} / \mathrm{m}^{2}$ showed a hazard ratio (HR) of 2.14 (95\% CI: 0.06-7.67) in men and an HR of 1.74 (95\% CI: 1.03-2.94) in women (20). A study compared a total of 4,977 patients with thyroid cancer and controls in the Korean National Health Insurance Service-Health Screening Cohort and reported that obesity increased the risk of thyroid cancer (21).

In summary, a higher increase in BMI seems to increase the risk of developing thyroid cancer, especially in men or in $\mathrm{BMI} \geq 30-35 \mathrm{~kg} / \mathrm{m}^{2}$.

Is obesity associated with recurrence of thyroid cancer? Is there any association with obesity and indicators of poor prognosis of thyroid cancer?

A retrospective study of Chinese PTC patients showed that the overweight group had a higher risk for ETE and advanced TNM III/IV stage. The obesity group was associated with ETE (13). A retrospective study of Korean PTC patients showed higher BMI was an independent predictor for multifocality and ETE in women (12). Another retrospective study of Polish PTC patients showed obese patients had a higher risk of minimal ETE, multifocality, and bilaterality (11).

A meta-analysis including 11 retrospective cohorts (mainly Asian) showed obesity was associated with tumor size, multifocality, ETE, and advanced TNM stage (9). Another meta-analysis of 15 studies (mainly Asian) showed obesity was associated with larger tumor size, increased rates of multifocality, ETE, and CLN spread (10).

A prospective study of European cohort analysis of 432 differentiated thyroid carcinoma (DTC) patients showed no single feature of advanced thyroid cancer was associated with obesity except microscopic ETE (OR 1.06) (22).

A large population-based study of US showed overweight and obesity were associated threefold and fivefold increased risks of large $(>4 \mathrm{~cm})$ PTCs compared with normal weight (23).

In summary, BMI seems to be associated with poor prognosis factors of PTC or DTC, such as ETE, multifocality, or tumor size, especially in Asian. Obesity might be related to ETE or multifocality, not to tumor recurrence of PTC or DTC. It is not easy to conclude based on previous papers. The several reasons seemed to affect different results: the diversity of ethnicity, or the influence of obesity on various races. 
Table 2 Univariate and multivariate analysis of the association of clinical recurrence with various clinicopathological parameters

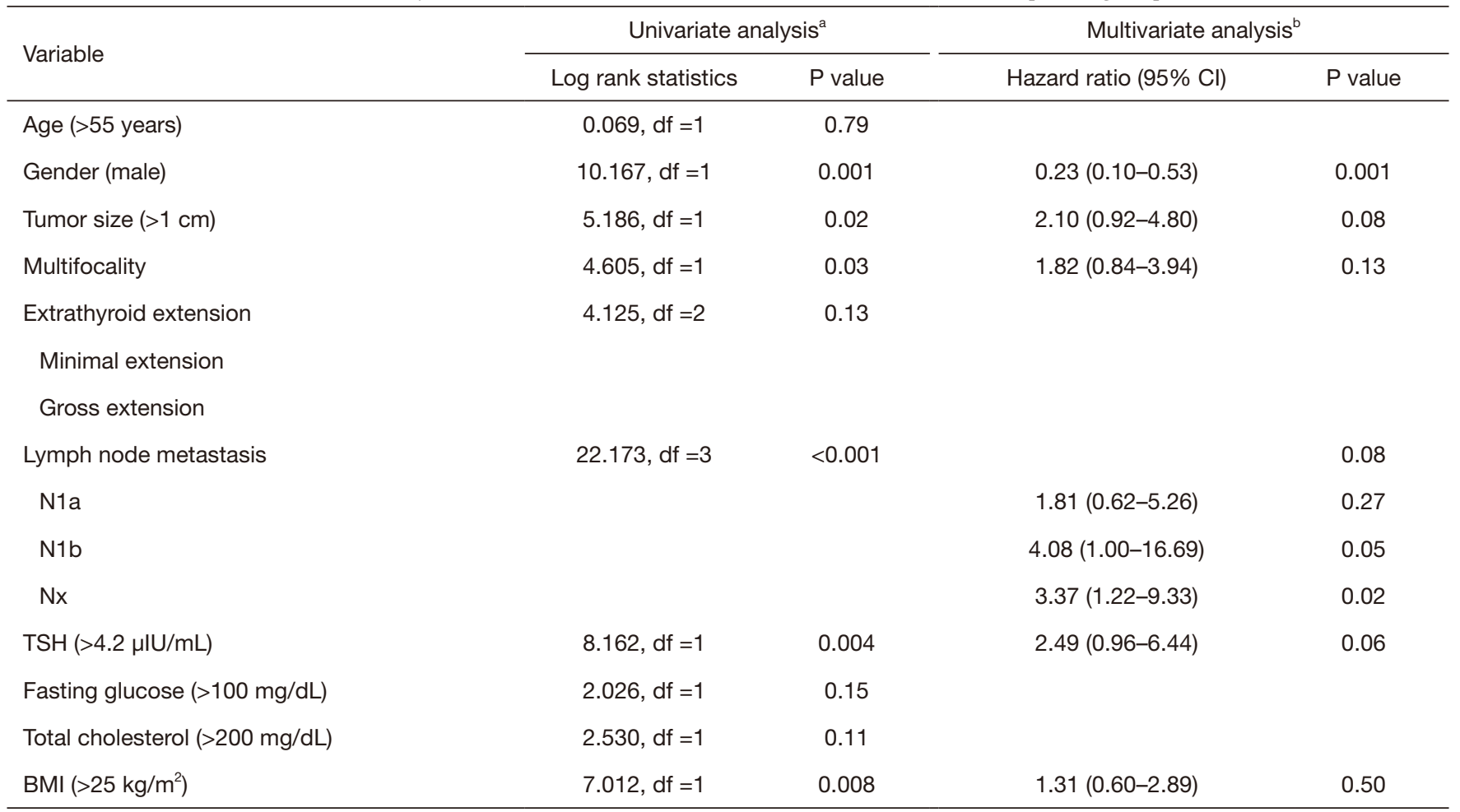

a , by the Kaplan-Meier method for recurrence with the log rank test; ${ }^{\mathrm{b}}$, by Cox's proportional hazard model and the forward stepwise method. $\mathrm{Cl}$, confidence interval; NA, not available; BMI, body mass index; TSH, thyroid stimulating hormone.

Table 3 Multivariate analysis of the association of BMI with various clinicopathological parameters

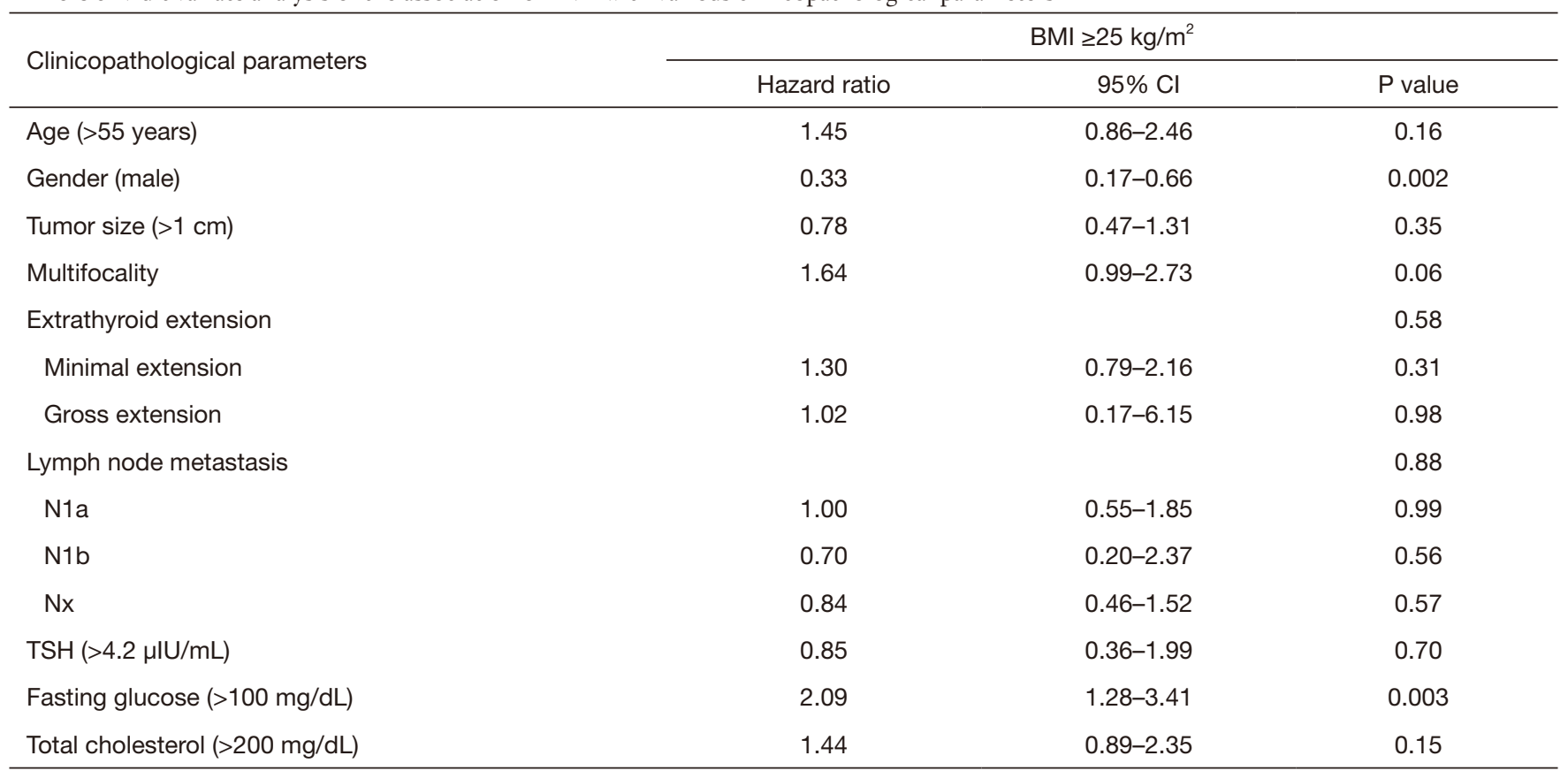

Statistical analysis performed by binary logistic regression analysis. $\mathrm{Cl}$, confidence interval; BMI, body mass index; TSH, thyroid stimulating hormone. 
Unlike other studies, this study showed overweight or obesity was not related to poor prognosis factors. Univariate analysis showed patients with overweight or obesity had higher multifocality and higher tumor recurrence compared to patients with non-obesity. This seems to be due to the small number of patients with a BMI $\geq 30 \mathrm{~kg} / \mathrm{m}^{2}$ in our study. Two meta-analyses showed obese group (BMI $\geq 30 \mathrm{~kg} / \mathrm{m}^{2}$ ) had larger tumor, increased rate of multifocality and ETE.

In addition, overweight or obesity was related to gender, serum fasting glucose level. Male is a strong risk factor of tumor recurrence. Some studies have suggested that the mortality rate in men can be twice as high as in women and that men have larger tumors (24). In this study, because the prevalence of overweight or obesity was higher in men, a univariate analysis may indicate that patients with overweight or obesity have a higher tumor recurrence rate than non-obese patients. And, Overweight or obesity patients had higher serum fating glucose level. Obesity can result in insulin hypersecretion and chronic low-grade tissue inflammation, which consequently causes insulin resistance in peripheral tissues. Insulin resistance can be exacerbated by increased free fatty acid flux, hyperleptinemia, and hyperglycemia, causing lipotoxicity and glucotoxicity, leading to $\beta$-cell failure and, eventually, type 2 diabetes mellitus (25). However, I did not analyze the association between insulin resistance and PTC because I had no laboratory results such as insulin, c-peptide, and triglyceride level.

This study has some limitations. First, there was no data on the overweight or obesity duration. Second, the subject of this study is a heterogeneous population about treatment modalities such as near-total or total thyroidectomy or lobectomy. Third, Nx accounted for a considerable part. I performed LN dissection when CLN metastasis was macroscopically confirmed. However, it is unlikely that this will affect the overall prognosis.

Overweight or obesity could affect the development of thyroid cancer. It could be associated with poor prognosis factors but not tumor recurrence. Although further research is needed, I suggest that obesity could belong to a poor prognosis factor of PTC.

\section{Conclusions}

In conclusion, overweight or obesity might be associated with poor prognosis factors. However, they might not be associated with tumor recurrences of PTC.

\section{Acknowledgments}

Funding: None.

\section{Footnote}

Reporting Checklist: The author has completed the STROBE reporting checklist. Available at https://gs.amegroups.com/ article/view/10.21037/gs-21-695/rc

Data Sharing Statement: Available at https://gs.amegroups. com/article/view/10.21037/gs-21-695/dss

Peer Review File: Available at https://gs.amegroups.com/ article/view/10.21037/gs-21-695/prf

Conflicts of Interest: The author has completed the ICMJE uniform disclosure form (available at https://gs.amegroups. com/article/view/10.21037/gs-21-695/coif). The author has no conflicts of interest to declare.

Ethical Statement: The author is accountable for all aspects of the work in ensuring that questions related to the accuracy or integrity of any part of the work are appropriately investigated and resolved. The study was conducted in accordance with the Declaration of Helsinki (as revised in 2013). The study was approved by Institutional Review Board of Inje University Sanggye Paik Hospital (No. SGPAIK 2021-11-027) and individual consent for this retrospective analysis was waived.

Open Access Statement: This is an Open Access article distributed in accordance with the Creative Commons Attribution-NonCommercial-NoDerivs 4.0 International License (CC BY-NC-ND 4.0), which permits the noncommercial replication and distribution of the article with the strict proviso that no changes or edits are made and the original work is properly cited (including links to both the formal publication through the relevant DOI and the license). See: https://creativecommons.org/licenses/by-nc-nd/4.0/.

\section{References}

1. Renehan AG, Tyson M, Egger M, et al. Body-mass index and incidence of cancer: a systematic review and metaanalysis of prospective observational studies. Lancet 2008;371:569-78. 
2. Steele CB, Thomas CC, Henley SJ, et al. Vital Signs: Trends in Incidence of Cancers Associated with Overweight and Obesity - United States, 2005-2014. MMWR Morb Mortal Wkly Rep 2017;66:1052-8.

3. Fang X, Wei J, He X, et al. Quantitative association between body mass index and the risk of cancer: A global Meta-analysis of prospective cohort studies. Int J Cancer 2018;143:1595-603.

4. Kyrgiou M, Kalliala I, Markozannes G, et al. Adiposity and cancer at major anatomical sites: umbrella review of the literature. BMJ 2017;356:j477.

5. Ma J, Huang M, Wang L, et al. Obesity and risk of thyroid cancer: evidence from a meta-analysis of 21 observational studies. Med Sci Monit 2015;21:283-91.

6. Schmid D, Ricci C, Behrens G, et al. Adiposity and risk of thyroid cancer: a systematic review and meta-analysis. Obes Rev 2015;16:1042-54.

7. Zhao ZG, Guo XG, Ba CX, et al. Overweight, obesity and thyroid cancer risk: a meta-analysis of cohort studies. J Int Med Res 2012;40:2041-50.

8. Matrone A, Ferrari F, Santini F, et al. Obesity as a risk factor for thyroid cancer. Curr Opin Endocrinol Diabetes Obes 2020;27:358-63.

9. Cui N, Sun Q, Chen L. A meta-analysis of the influence of body mass index on the clinicopathologic progression of papillary thyroid carcinoma. Medicine (Baltimore) 2021;100:e26882.

10. O'Neill RJ, Abd Elwahab S, Kerin MJ, et al. Association of BMI with Clinicopathological Features of Papillary Thyroid Cancer: A Systematic Review and Meta-Analysis. World J Surg 2021;45:2805-15.

11. Kaliszewski K, Diakowska D, Rzeszutko M, et al. Obesity and Overweight Are Associated with Minimal Extrathyroidal Extension, Multifocality and Bilaterality of Papillary Thyroid Cancer. J Clin Med 2021;10:970.

12. Kim SK, Woo JW, Park I, et al. Influence of Body Mass Index and Body Surface Area on the Behavior of Papillary Thyroid Carcinoma. Thyroid 2016;26:657-66.

13. Wang H, Wang P, Wu Y, et al. Correlation between obesity and clinicopathological characteristics in patients with papillary thyroid cancer: a study of 1579 cases: a retrospective study. PeerJ 2020;8:e9675.

14. WHO Expert Consultation. Appropriate body-mass index for Asian populations and its implications for policy and intervention strategies. Lancet 2004;363:157-63.

15. Di Angelantonio E, Bhupathiraju ShN, Wormser D, et al. Body-mass index and all-cause mortality: individual- participant-data meta-analysis of 239 prospective studies in four continents. Lancet 2016;388:776-86.

16. Seo MH, Kim YH, Han K, et al. Prevalence of Obesity and Incidence of Obesity-Related Comorbidities in Koreans Based on National Health Insurance Service Health Checkup Data 2006-2015. J Obes Metab Syndr 2018;27:46-52.

17. Pacific. WHOROftW. The Asia-Pacific perspective: redefining obesity and its treatment. Health Communications Australia. 2000.

18. Song YM, Sung J, Ha M. Obesity and risk of cancer in postmenopausal Korean women. J Clin Oncol 2008;26:3395-402.

19. Leitzmann MF, Brenner A, Moore SC, et al. Prospective study of body mass index, physical activity and thyroid cancer. Int J Cancer 2010;126:2947-56.

20. Meinhold CL, Ron E, Schonfeld SJ, et al. Nonradiation risk factors for thyroid cancer in the US Radiologic Technologists Study. Am J Epidemiol 2010;171:242-52.

21. An SY, Kim SY, Oh DJ, et al. Obesity is positively related and tobacco smoking and alcohol consumption are negatively related to an increased risk of thyroid cancer. Sci Rep 2020;10:19279.

22. Grani G, Lamartina L, Montesano T, et al. Lack of association between obesity and aggressiveness of differentiated thyroid cancer. J Endocrinol Invest 2019;42:85-90.

23. Kitahara CM, Pfeiffer RM, Sosa JA, et al. Impact of Overweight and Obesity on US Papillary Thyroid Cancer Incidence Trends (1995-2015). J Natl Cancer Inst 2020;112:810-7.

24. Tam AA, Özdemir D, Çuhacı N, et al. Association of multifocality, tumor number, and total tumor diameter with clinicopathological features in papillary thyroid cancer. Endocrine 2016;53:774-83.

25. Chen W, Balland E, Cowley MA. Hypothalamic Insulin Resistance in Obesity: Effects on Glucose Homeostasis. Neuroendocrinology 2017;104:364-81.

Cite this article as: Kim JM. The clinical importance of overweight or obesity on tumor recurrence in papillary thyroid carcinoma. Gland Surg 2022;11(1):35-41. doi: 10.21037/gs-21695 